Original Research

\title{
Photodegradation Characteristics of Dissolved Organic Matter (DOM) in Alpine Soils of the Eastern Margin of Tibetan Plateau
}

\author{
Shu Wang ${ }^{1}$, Jihong Qin², Hui Sun ${ }^{1 *}$, Wenqing Chen ${ }^{1}$, Bingxin Xie ${ }^{1}$ \\ ${ }^{1}$ College of Architecture \& Environment, Sichuan University, Chengdu 610065, China \\ ${ }^{2}$ School of Architecture and Civil Engineering, Chengdu University, Chengdu 610065, China
}

Received: 21 May 2020

Accepted: 15 October 2020

\begin{abstract}
The dissolved organic matter (DOM) in alpine soils of the eastern edge of the Qinghai-Tibet Plateau have unique optical properties. Therefore, a thorough understanding of the photodegradation characteristics of DOM helps in revealing regional DOC dynamics and carbon cycle at the water-land interface in alpine soils. Typical soil samples of the subalpine forest and peat wetland were collected and DOM were extracted and cultivated, ultraviolet-visible absorbance and excitation emission matrix fluorescence spectroscopy with two-dimensional correlation spectrum (2D-COS) and fluorescence regional integration (FRI) were used to characterize the environmental behavior responses to light irradiation. The results showed that the first-order decay constants and photodegradation rates of subalpine forest soil and alpine peat wetland soil were $0.0777 \mathrm{~d}^{-1}, 0.0907 \mathrm{~d}^{-1}$ and $42.06 \%, 45.47 \%$, respectively. The aromaticity and humification degree of CDOM in alpine soils were decreased with increasing exposure time. The FDOM in alpine soil showed four components (C1-C4), all components degraded in different degrees under light. According to the synchronous and asynchronous map, tyrosine- and tryptophan-like FDOM showed higher susceptibility in subalpine forest soil, while fulvic acid-like and humic acid-like FDOM showed higher susceptibility in alpine peat wetland soil. It confirmed that DOM of alpine soils showed good photodegradation characteristics, light might increase the instability of DOM in alpine soils.
\end{abstract}

Keywords: Tibetan Plateau, dissolved organic matter (DOM), photodegradation, excitation-emission matrix, two-dimensional correlation spectrum (2D-COS)

*e-mail: sunhuifiles@gmail.com 


\section{Introduction}

Dissolved organic matter (DOM) refers to the soluble organic matter can pass through a $0.45 \mu \mathrm{m}$ filter membrane. DOM contains chromophoric dissolved organic matter (CDOM) and fluorescent dissolved organic matter (FDOM), which are responsible for absorbing and emitting light, respectively. CDOM is a unique component of DOM that can strongly absorb ultraviolet and visible light [1]. Also, a fraction of CDOM emitting fluorescence by light absorption is recognized as FDOM [2]. CDOM is a major driver of light penetration that modulates primary production, its fluorescence characteristics provide important information for understanding DOM structure and resolving DOM characteristics. CDOM and FDOM effectively absorb ultraviolet and visible light and subsequently influence the light condition in the euphotic zone. As a natural "light barrier" in plateau soil, DOM plays an important role in protecting organisms in the upper soil from harmful UV radiation [3]. Since the photodegradation reaction of DOM is often accompanied by the change of structure and molecular weight composition $[4,5]$, it can increase the content of bioavailable carbon matrix in the soil, thereby promoting the increase of the productivity of microorganisms. The increase in carbon matrix content also has a significant impact on the biogeochemical cycle of bioavailable elements in the soil [5].

The photoreaction of DOM affects the light environment of the soil. The photodegradation processes play an important role in releasing the elements bound by biologically refractory forms in the environment, and are gradually considered to be an important factor in the biogeochemical cycle. Degraded organic molecules are converted into low-molecularweight compounds and inorganics, which increases their bioavailability and thus their mobility across environmental compartments [6]. Increasing attention has been paid to the role of the photodegradation in the biogeochemical cycle, especially for those environments that are inherently slow due to low temperatures, lack of water, or biological processes that occur in them [7].

Two-dimensional correlation spectroscopy (2D-COS) can reflect the sensitivity and order of change of the spectral response to external environment changes through synchronous and asynchronous graphs[8]. In recent years, 2D-COS has gradually been used to analyze the changes of spectral characteristics of CDOM under external disturbance (such as catalytic photodegradation[9], metals [10-12] and biodegradation [13]), while CDOM is used in photodegradation were not reported. Soil carbon storage of subalpine forest and peat wetland in the eastern margin of Qinghai-Tibetan Plateau is the most important cold carbon pool in the whole Plateau, and the ultraviolet radiation intensity is relatively high. The photodegradation process is an important degradation and transformation way of DOM in the natural soil, which has an important impact on the soil ecological environment, water environment and water ecology of the natural surface water body in the eastern margin of the Tibetan Plateau. Based on the analysis of the three-dimensional fluorescence spectrum and UV-Vis absorption spectrum characteristics of DOM in the eastern margin of Qinghai-Tibetan Plateau, this paper attempts to use two-dimensional Correlation spectroscopy (2D-COS) reveals the sensitivity and response sequence of DOM in the natural soil of high altitude area under the light disturbance, in order to provide a basis for the study of soil environmental management in plateau areas, and also has an important theoretical significance for the study of carbon cycle and water land interface carbon exchange in the eastern margin of Qinghai-Tibetan Plateau under the background of global change.

\section{Experimental}

\section{Sites Description}

The sampling area of this study was located on the eastern margin of the Tibetan Plateau, in Majiagou in Xiaojin County and Zoige Wetland in the Aba Autonomous Prefecture of Sichuan Province. The Majiagou area has a typical plateau alpine deep valley topography. The Mountains are southwestern, the terrain is high in the northwest and low in the southeast. Majiagou has an altitude of 3,090 3,900 m, and there are several snow peaks over 5,000 meters in the ditch. There are new glaciers at the tail of the ditch, and the polar geomorphological features are obvious. The Zoige Wetland is one of the large peat swamps on the Tibetan Plateau in China. It has a strong water storage capacity, and its Zoige grassland is known as the "oasis of the Sichuan Plateau". The Zoige Wetland has an altitude of 3,400 3,550 $\mathrm{m}$, an average annual temperature of about $1.1^{\circ} \mathrm{C}$, and an average annual precipitation of about $650 \mathrm{~mm}$. Some areas were seasonal freeze-thaw soils, forming a special small peat hilly marsh terrain. Vegetation belongs to the non-zonal vegetation of the Tibetan Plateau, and is dominated by alpine meadows and alpine wetlands. The community is dominated by sedges and grasses, which have good structural stability, but the system is self-recovering. It is weak and is one of the important high-quality alpine pastures on the Tibetan Plateau.

\section{Soil Sampling and Pretreatment}

Soil samples for this study were collected in Zoige County and Xiaojin County, of Aba Tibetan and Qiang Autonomous Prefecture, Sichuan in mid-November, 2018. Sample plots were selected from Majiagou in Xiaojin County (A, subalpine forest) and Zoige Wetland (B, alpine peat wetland) (as shown as Fig. 1.) for of surface soil sampling $(0 \sim 10 \mathrm{~cm})$. A 20 -m horizontal sampling zone was arranged for each sampling area, 


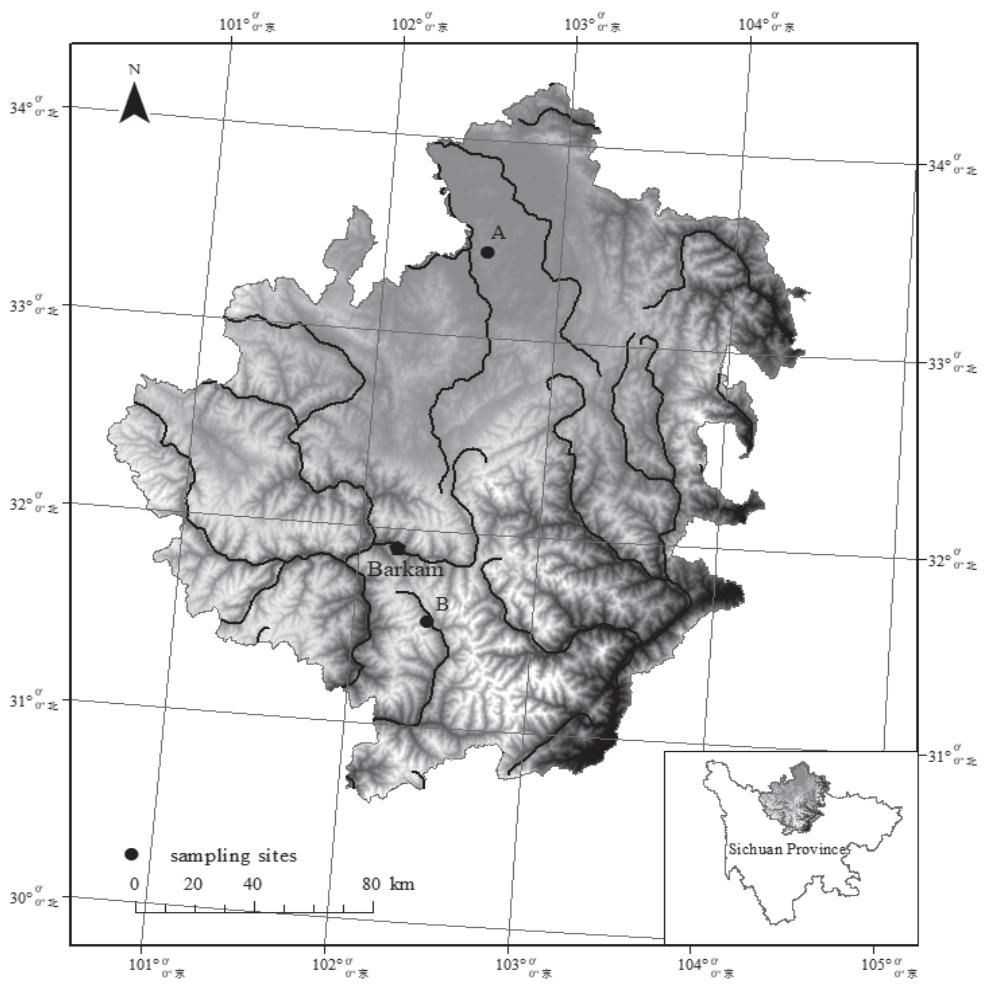

Fig. 1. Schematic map of the target area and the sampling sites.Note: A and B represented subalpine forest, alpine peat wetland, respectively.

and the sampling zone was set with three repetitions, which each repetition having an equal mixing amount of 10 sampling points along the sample strip. When sampling, we removed the snow and grass layers on the surface. After sampling, we removed the sand, roots, plant residues, etc. in the soil, ground and passed these items through a 100 meshes sieve, mixed with the sieved soil and stored at $4{ }^{\circ} \mathrm{C}$. The soil samples were brought back to the laboratory for extraction of DOM and analysis of other properties of the soil.

\section{Soil DOM Extraction and Chemical Analysis}

$\mathrm{KCl}$ solution was chosen as the extractant following Jones and Willett [14], Gabor et al. [15] and XIE Wenming et al. [16] Twenty grams of fresh soil samples were placed into an Erlenmeyer flask and extracted with $\mathrm{KCl}$ at $1.50 \mathrm{~mol} / \mathrm{L}$ concentrations, solid to liquid ratios (SLR) of 1:5, and extraction times of $150 \mathrm{~min}$, shaking at $180 \mathrm{r} / \mathrm{min}$ at room temperature. The suspensions were then centrifuged at $1800 \times \mathrm{g}$ and $4^{\circ} \mathrm{C}$ for $10 \mathrm{~min}$ and filtered through a $0.45-\mu \mathrm{m}$ cellulose nitrate membrane filter on a vacuum system. All extractions were performed in triplicate for each sample. The DOM extracts were collected in Teflon sampling bottles. The sample bottle was washed once with soapy water, washed 6 times with ultrapure water, and dried in an oven at $60^{\circ} \mathrm{C}$ before use. The extract was stored in a refrigerator at $4^{\circ} \mathrm{C}$ in the dark, and the sample was immediately analyzed after the extraction. The soil DOM $\mathrm{pH}$ level was determined using a $\mathrm{pH}$ detector. Soil sample total nitrogen (TN) and total organic carbon (TOC) were determined by Elementar elemental analyzer (Vario MACRO cube); dissolved organic carbon (DOC) and dissolved organic nitrogen (DON) were determined in a total organic carbon total nitrogen analyzer (Milti N/C 2100S, Jena, Germany); dissolved phosphorus (DP) was determined by ICP-MS analysis using Millipore ultrapure water as a blank.

\section{Photodegradation Experiment}

In November 2018, the photodegradation experiment of two kinds of soil DOM under natural solar radiation was conducted in the high altitude area of Liangshan Yi Autonomous Prefecture, Sichuan. The $500 \mathrm{~mL}$ soil DOM samples from the same soil were placed in two $250 \mathrm{~mL}$ quartz beakers, one of which was wrapped in tin foil to avoid light as a control. The sample was irradiated for $7 \mathrm{~h}$ every day (10:00 17:00), and the rest of the time was stored in the dark. Samples were taken at the beginning of the experiment at $0 \mathrm{~d}, 0.5 \mathrm{~d}, 1 \mathrm{~d}$, $2 \mathrm{~d}, 3 \mathrm{~d}, 4 \mathrm{~d}$ and $5 \mathrm{~d}$, and the samples were stored in a refrigerator at $4^{\circ} \mathrm{C}$ protected from light. During the experiment, the temperature and ultraviolet radiation intensity were measured every 2 h (LS 125 UV intensity meter). At the end of the irradiation experiment, all samples were brought back to the laboratory for immediate analysis. The daily temperature and UV radiation intensity during the experiment are shown in Fig. 2. 


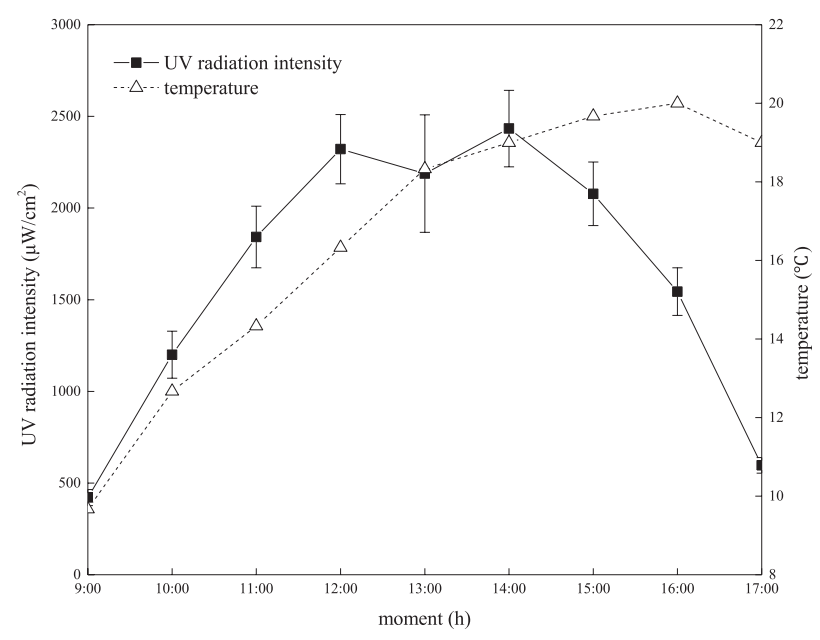

Fig. 2. Diurnal distribution of temperature and UV radiation intensity distribution during the irradiation experiment.

\section{Determination of Three-Dimensional Excitation Emission Matrix Fluorescence}

The DOM three-dimensional fluorescence spectra and ultraviolet-visible spectra of all soil samples were measured using a fluorescence spectrometer (Aqualog, Horiba). The measurement conditions were as follows: $150 \mathrm{~W}$ xenon lamp was the excitation light source, PMT voltage was set to $700 \mathrm{~V}$, and $1 \mathrm{~cm}$ quartz cuvettes were used; scanning spectrum was used for automatic calibration of the instrument; the scanning wavelength range is the excitation wavelength (ex) of $240 \sim 550 \mathrm{~nm}$, emission wavelength (em) is 214 to 619 $\mathrm{nm}$; and the interval and slit width are $3.0 \mathrm{~nm}$ and $2.5 \mathrm{~nm}$, respectively. Using Millipore ultrapure water as a blank, the system automatically corrects Raman scattering and Rayleigh scattering. The fluorescence intensity is indicated in units of A.U. (Arbitrary Unit).

\section{Data Processing Analysis}

Soil DOM fluorescence parameters: Fluorescence absorption coefficient $a_{\lambda}$ was calculated by the nonlinear regression method. The relative concentration of soil CDOM was expressed by the absorption coefficient $a_{355}\left(\mathrm{~m}^{-1}\right)$ at $355 \mathrm{~nm}$. Using DOM threedimensional fluorescence data to calculate each parameter: fluorescence absorption coefficient $a_{355}$, the three-dimensional fluorescence data of DOM were used to calculate $\mathrm{SUVA}_{254}$ (specific UV absorbance at $254 \mathrm{~nm}$ ), spectral slope ratio $S_{R}$ (the ratio of 275 295 $\mathrm{nm}$ band and 350 400 nm band absorption spectrum slope), fluorescence index FI $(e x=370 \mathrm{~nm}$, em $=470 \mathrm{~nm} / 520 \mathrm{~nm})$ and humification index $\operatorname{HIX}_{\mathrm{b}}(\mathrm{ex}=254 \mathrm{~nm}$, $\left.\mathrm{em}=\int(435 \sim 480 \mathrm{~nm}) /\left[\int(300 \sim 345) \mathrm{nm}+\int(435 \sim 480 \mathrm{~nm})\right]\right)$ [17].

The photodegradation rate constant $\mathrm{k}$ and half-life $t_{1 / 2}$ of CDOM from two soils in the Western Sichuan Plateau were fitted by the first-order degradation kinetic equation:

$$
\begin{gathered}
\ln \left(\frac{\mathrm{C}}{\mathrm{C}_{0}}\right)=-\mathrm{kt}+\mathrm{A} \\
\mathrm{t}_{1 / 2}=0.693 / \mathrm{k}
\end{gathered}
$$

...where $\mathrm{C}_{0}$ is the initial concentration of CDOM in soil samples $\left(\mathrm{m}^{-1}\right), \mathrm{C}$ is the concentration of CDOM in soil samples at a certain light time $\left(\mathrm{m}^{-1}\right), \mathrm{t}$ is the light time (d), $k$ is the photodegradation rate constant $\left(\mathrm{d}^{-1}\right), \mathrm{t}_{1 / 2}$ is the half-life (d), A is the constant [18]. The value of $\mathrm{k}$ is directly proportional to the photodegradation rate.

Fluorescence Regional Integration: The threedimensional fluorescence spectrum of soil DOM generally divides the two-dimensional fluorescence region formed by the excitation wavelength and emission wavelength into five characteristic peak regions [19], representing five different types of organic matter. The excitation wavelength and emission wavelength range of these five fluorescent peaks are shown in Table 1.

Three-dimensional integration of the fluorescence peak region was calculated using the Origin 9.0 software integral calculation to calculate the specific fluorescence region volume $\left(\phi_{\mathrm{i}}\right)$. The formula is as follows:

$$
\phi_{i}=\int_{e x} \int_{e m} I\left(\lambda_{e x} \lambda_{e m}\right) \mathrm{d} \lambda_{e x} d \lambda_{e m}
$$

...where $\mathrm{I}\left(\lambda_{e x} \lambda_{e m}\right)$ is the excitation wavelength range and emission wavelength range for the specific fluorescence peak, and the spectral intensity of the soil DOM fluorescence characteristic component can be calculated.

Table 1. Characteristics of five common fluorescent peaks in three-dimensional fluorescence of water-soluble organic matter (DOM).

\begin{tabular}{|c|c|c|}
\hline Fluorescence peak & Fluorophore & Fluorescence peak excitation and emission wavelength range \\
\hline Peak I & Aromatic protein I (tyrosine) & $\lambda_{e x}=200-250 \mathrm{~nm}, \lambda_{e m}=280-330 \mathrm{~nm}$ \\
\hline Peak II & Aromatic protein II (BOD $\left.)_{5}\right)$ & $\lambda_{e x}=200-250 \mathrm{~nm}, \lambda_{e m}=330-380 \mathrm{~nm}$ \\
\hline Peak III & Fulvic acid-like & $\lambda_{e x}=200-250 \mathrm{~nm}, \lambda_{e m}=380-550 \mathrm{~nm}$ \\
\hline Peak IV & Microbial metabolites (tryptophan) & $\lambda_{e x}=250-450 \mathrm{~nm}, \lambda_{e m}=280-330 \mathrm{~nm}$ \\
\hline Peak V & Humic acid-like (macromolecule humic acid) & $\lambda_{e x}=250-450 \mathrm{~nm}, \lambda_{e m}=380-550 \mathrm{~nm}$ \\
\hline
\end{tabular}


a)

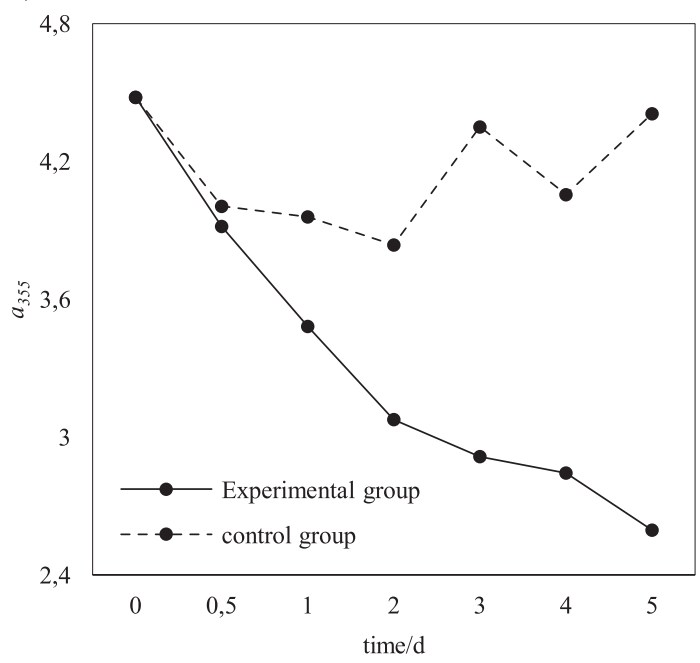

b)

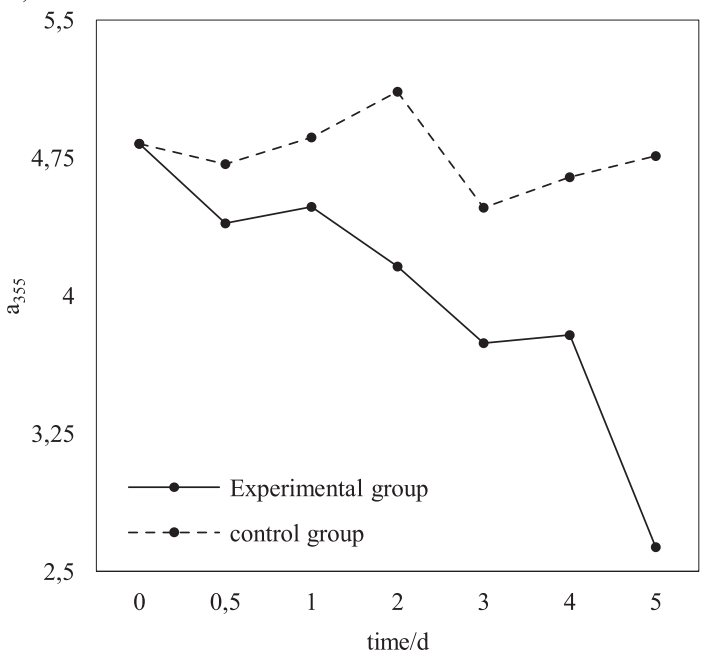

Fig. 3. Photodegradation characteristics of CDOM in alpine soils in the eastern margin of Tibetan Plateau.

The specific region integral volume, i.e. the cumulative fluorescence intensity of organic matter with similar properties, is calculated to reflect the relative content of the specific structural organics in this region.

\section{Results and Discussion}

\section{Photodegradation Characteristics of Soil CDOM}

To describe the degradation process of CDOM quantitatively, the parameters $a_{355}$ was considered as quantitative indicators of chromophoric DOM (CDOM), so as to further reveal the photodegradation behavior of CDOM (Fig. 3). Compared with the control group without light transmission, both soil CDOM experimental groups showed good photodegradation characteristics, and the content of CDOM decreased with the increase of irradiation time. As can be seen from the figure, the photodegradable DOM in the soil was removed exposure to light. Exposure to light reduced the UV light-absorbing ability of DOM and, to a lesser extent, its concentration. Reactions induced by solar radiation may oxidize DOM to inorganic $\mathrm{C}$ or break large molecules into smaller ones.

The photodegradation of CDOM accords with the first-order reaction kinetic equation. The photodegradation rate constant $(\mathrm{k})$ and half-life $\left(t_{1 / 2}\right)$ of the two kinds of soil CDOM are fitted by the equation (Table 2). The reason for the difference of photodegradation rate and rate of the two kinds of soil may be related to the background value, source and structure of CDOM. The plateau peat wetland soil has obvious humification characteristics and obvious endogenous characteristics. However, the humification characteristics of CDOM in subalpine forest soils are weak and have both internal and external sources.

\section{Component Characteristics of FDOM in Alpine Soils}

All the fluorescence spectral data of the alpine soil samples were decomposed by the PARAFAC modeling. PARAFAC distinguished four organic components from the DOM of plateau soil, including one fulvic acid-like component (C1), one humic acid-like component (C3), and two protein-like components (C2 and $\mathrm{C} 4)$, as shown in Fig. 4.

PARAFAC component $\mathrm{C} 1$ shows two peaks at ex/ em wavelengths of 250/450 $\mathrm{nm}$ and $300 / 540 \mathrm{~nm}$. This spectral feature is considered to be fulvic acid-like fluorescence, consistent with previous studies [20, 21]. C1 mainly comes from terrestrial organic precursors, such as forest streams, soil extracts, wetlands and fallen leaves [22]. Wet precipitation generally leads to an increase in $\mathrm{Cl}$, which can be ascribed to enhanced landbased inputs from stormwater runoff [23]. PARAFAC component $\mathrm{C} 2$ shows dominating peak at $285 / 335 \mathrm{~nm}$ (ex/em). This peak was attributed to tryptophan-like peak T constituents [24], which was frequently detected in the aquatic environments affected by anthropogenic input. The EEM spectrum of $\mathrm{C} 3$ has a peak (ex/em) at $270 / 500 \mathrm{~nm}$, which was the integration of terrestrial

Table 2. Comparison of photodegradation rate of CDOM in A and B.

\begin{tabular}{|c|c|c|c|c|c|c|}
\hline $\begin{array}{c}\text { Research } \\
\text { object }\end{array}$ & Light source & $\begin{array}{c}\text { Irradiation } \\
\text { time }\end{array}$ & $\begin{array}{c}\text { Degradation } \\
\text { rate } / \%\end{array}$ & $\begin{array}{c}\text { Photodegradation rate } \\
\text { constant }(\mathrm{k})\end{array}$ & $\begin{array}{c}\text { Half-life } \\
\left(\mathrm{t}_{1 / 2}\right)\end{array}$ & $\begin{array}{c}\text { CDOM characterization } \\
\text { index }\end{array}$ \\
\hline $\mathrm{A}$ & Natural light & $5 \mathrm{~d}$ & $42.06 \%$ & 0.0777 & $8.92 \mathrm{~d}$ & $\mathrm{a}_{355}$ \\
\hline $\mathrm{B}$ & Natural light & $5 \mathrm{~d}$ & $45.47 \%$ & 0.0907 & $7.64 \mathrm{~d}$ & $\mathrm{a}_{355}$ \\
\hline
\end{tabular}



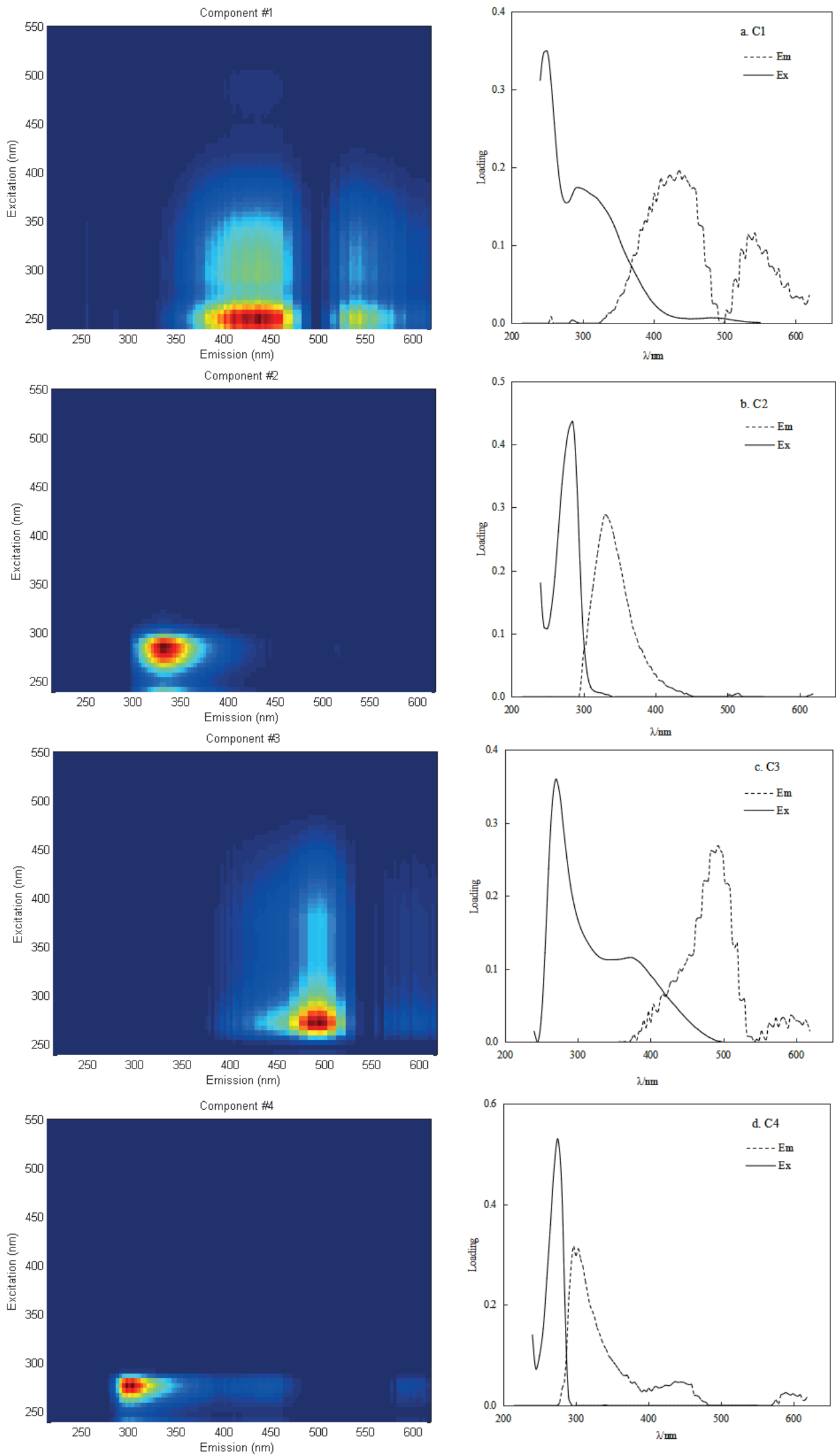

Fig. 4. EEMs and loadings of four FDOM components in alpine soils in the eastern margin of Tibetan Plateau. 
Table 3. Degradation characteristics of four FDOM components in alpine soils in the eastern margin of Tibetan Plateau.

\begin{tabular}{|c|c|c|c|c|c|c|}
\hline \multirow{2}{*}{ Soil samples } & \multirow{2}{*}{ Time/d } & \multicolumn{5}{|c|}{ Degradation rate/\% } \\
\cline { 3 - 7 } & & $\mathrm{C} 1$ & $\mathrm{C} 2$ & $\mathrm{C} 3$ & $\mathrm{C} 4$ & total \\
\hline $\mathrm{A}$ & 5 & 51.05 & 65.03 & 49.75 & 67.19 & 45.00 \\
\hline $\mathrm{B}$ & 5 & 59.65 & 66.63 & 64.23 & 28.05 & 57.05 \\
\hline
\end{tabular}

humic acid-like fluorescence peak A and peak C [24, 25]. Lee et al. [26] reported that short-wavelength fluorophores are associated with the presence of low aromatic organic components, while long-wavelength fluorescent organic components are associated with high aromatic polycondensation structure organics. The PARAFAC component $\mathrm{C} 4$ has a maximum at 275/300 nm (ex/em), and this peak in the EEM spectrum represents a tyrosine-like peak B component [24, 27]. The results showed that DOM in alpine soil samples contained almost all types of dissolved amino acids (tyrosine- and tryptophan-like components).

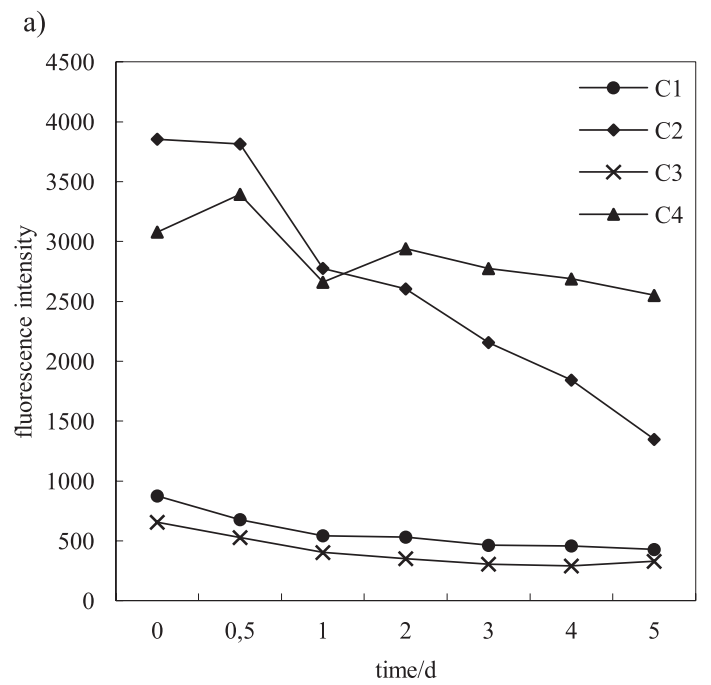

b)

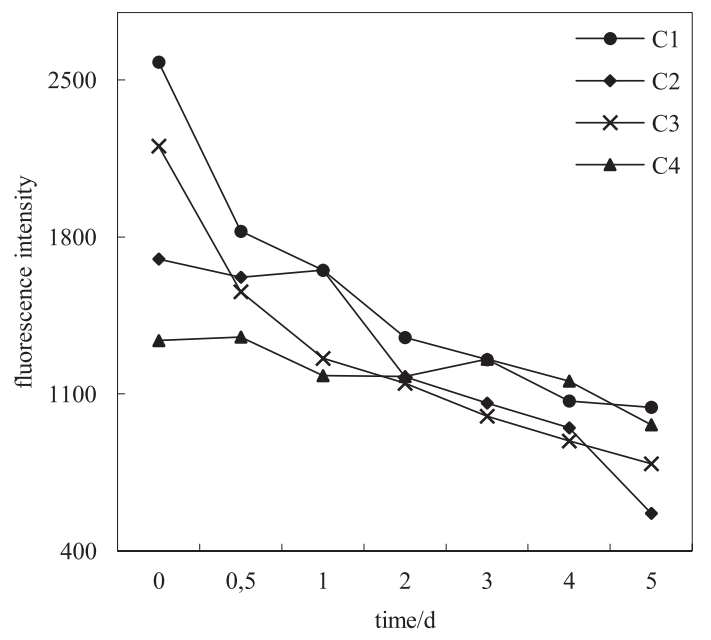

Fig. 5. Degradation characteristics of four FDOM components in alpine soils in the eastern margin of Tibetan Plateau.

\section{Photodegradation Characteristics of Soil FDOM}

All components of FDOM degraded in different degrees under light (Table 3). The photodegradation of FDOM fluorescence components in forest soil and peat wetland soil was different. The degradation rates of FDOM in forest soil and peat soil were $45.00 \%$ and $57.05 \%$ respectively. The degradation rate of tyrosinelike component $\mathrm{C} 4$ of FDOM is the lowest, which indicates that tyrosine-like component may not absorb visible light strongly, while other components can absorb visible light strongly. There was rich humus in peat wetland soil of plateau, so the fluorescence intensity of humus like component in alpine peat wetland soil is higher than that in subalpine forest soil.

As shown in Fig. 5, the changes of fluorescence components in the forest and peat wetland soils in the eastern margin of Qinghai-Tibet Plateau with the time of illumination are shown. As a whole, the fluorescence intensity of protein-like components in the subalpine forest soils is higher than that of other components, while the components of fulvic acid-like and humic acid-like in the peat wetland soils are higher. Humic acid-like and fulvic acid-like decreased significantly with the increase of light time, which indicated that they could absorb visible light and transform macromolecular matter into small molecular matter. In the process of photodegradation, protein-like FDOM has a high fluorescence intensity phenomenon, which may be due to the light will change the structure of FDOM, making it more difficult to be utilized by microorganisms, resulting in the accumulation of protein-like FDOM [28].

\section{Photodegradation Characteristics of Soil DOM Characteristic Parameters}

The three-dimensional fluorescence spectrum characteristic parameters FI, HIX ${ }_{b}$ and UV-Vis absorption spectrum characteristic parameters SUVA $_{254}$ and $S_{R}$ were selected to analyze the photodegradation behavior of DOM in two kinds of soils in the eastern margin of Qinghai-Tibetan Plateau. It was found that the DOM of forest soil and peat wetland soil in the plateau presented different changes in the photodegradation process (Fig. 6).

Generally speaking, the fluorescence index (FI) can be reflected the relative contribution rate of aromatic and non-aromatic amino acids to the fluorescence 

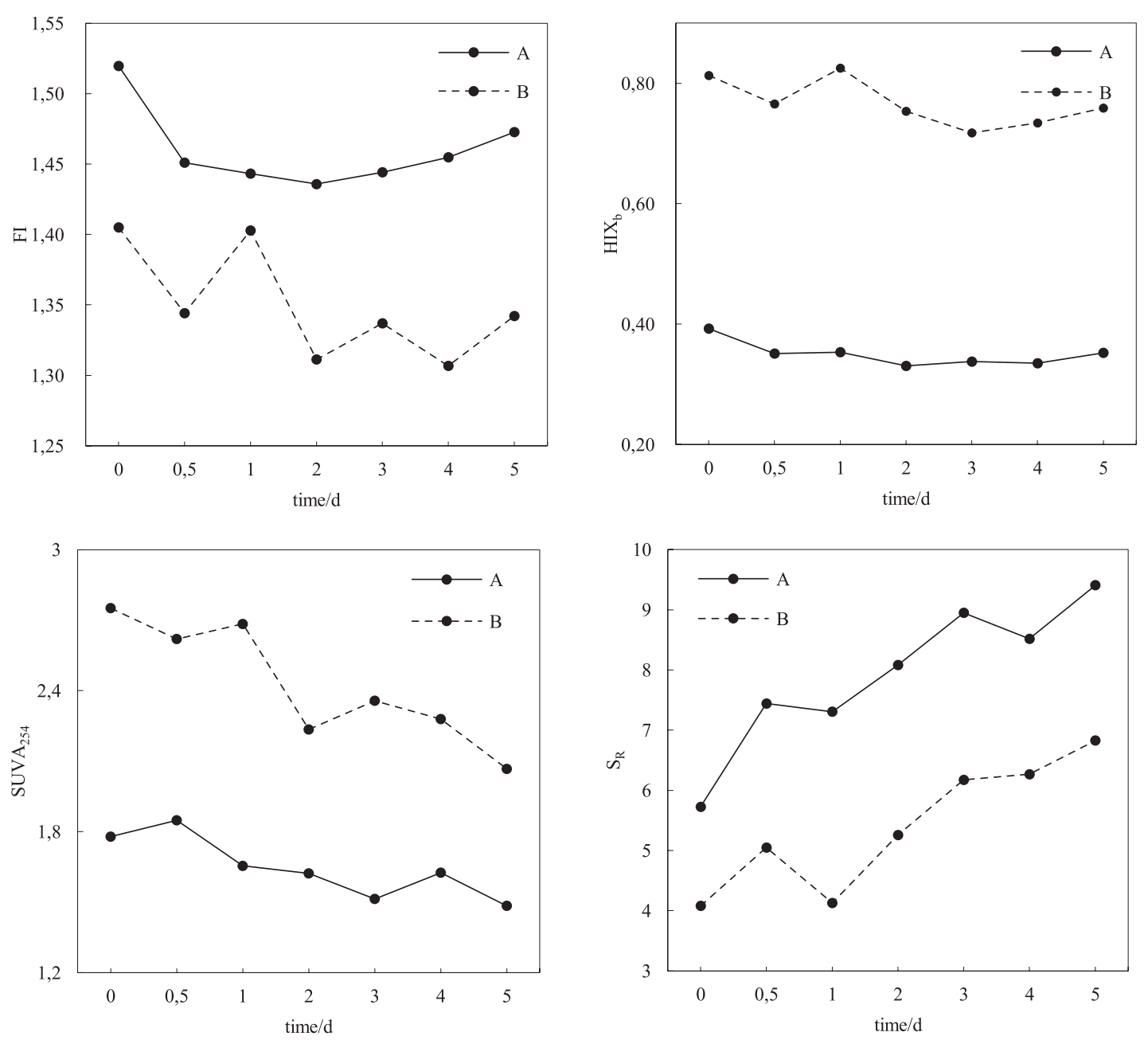

Fig. 6. Photodegradation characteristics of four DOM parameters in alpine soils.

intensity of DOM, and can be applied to identify DOM sources and the degree of degradation, such as autochthonous $(>1.9)$ and allochthonous sources $(<1.4)[29,30]$. With the increase of light irradiation time, the endogenous characteristics of FDOM in the subalpine forest soil gradually weakened. The soil FDOM of the alpine peat wetland has both internal and external source characteristics. During the process of illumination, the FI value of peat wetland soil changes violently, and finally the input characteristics of external sources are gradually dominant. The humification index HIX $_{b}$ indicates the humification degree of FDOM. HIX values generally increase as biomass decomposition $[30,31]$. The higher the value, the higher the degree of DOM humification, while low HIX values indicate that the non-humified structures were dominated in organic components. The humification degree of the alpine peat wetland soil is higher than that of the subalpine forest soil, and the humification degree of forest and peat wetland soil in the eastern margin of QinghaiTibetan Plateau decreases continuously in the process of illumination. Before and after light, although the humification degree of alpine forest soils decreased, the soil FDOM still had the characteristics of autogenic origin; alpine peatland soils changed from having both internal and external input characteristics to external input characteristics.

SUVA $_{254}$ has been diffusely applied to evaluate the aromaticity of CDOM [32]. The overall value of $\mathrm{SUVA}_{254}$ of alpine peatland soil is higher than that of subalpine forest soil, showing a gradual trend with the increase of light time. The five-day degradation rates of $\mathrm{SUVA}_{254}$ of peat wetland soil and forest soil in plateau are $24.87 \%$ and $16.54 \%$ respectively. This is because the aromatic carbon ring decomposes after the high energy ultraviolet (280-400 nm) absorbed by the CDOM in plateau soil, resulting in the formation of CDOM with less aromaticity, which leads to the aromaticity [7]. The spectral slope ratio $S_{R}$ reflects the change of soil CDOM source composition and structure, and the value is inversely proportional to the DOM molecular weight [33]. $S_{R}$ of peat wetland soil and forest soil increased steadily with the increase of degradation time, indicating that the endogenous characteristics of CDOM decreased gradually in the process of photodegradation.

As a whole, CDOM of peat wetland soil and forest soil in plateau showed a similar trend in the process of photodegradation, but the degradation characteristics 
a)

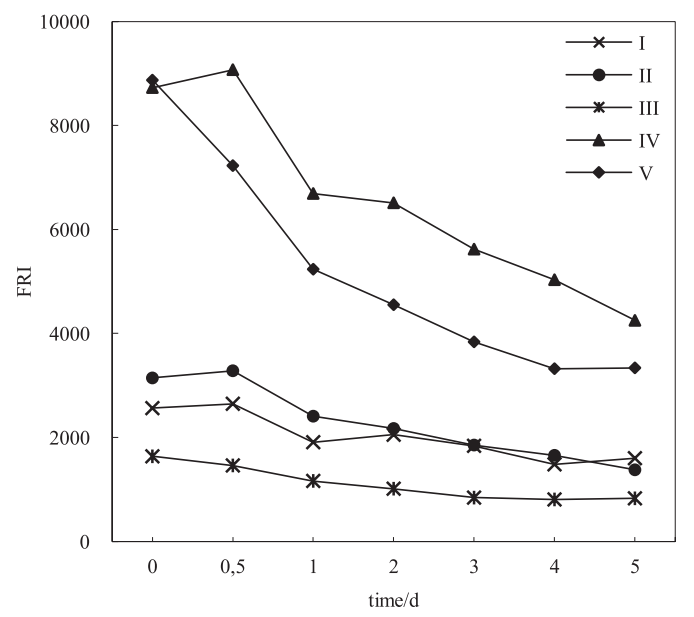

b)

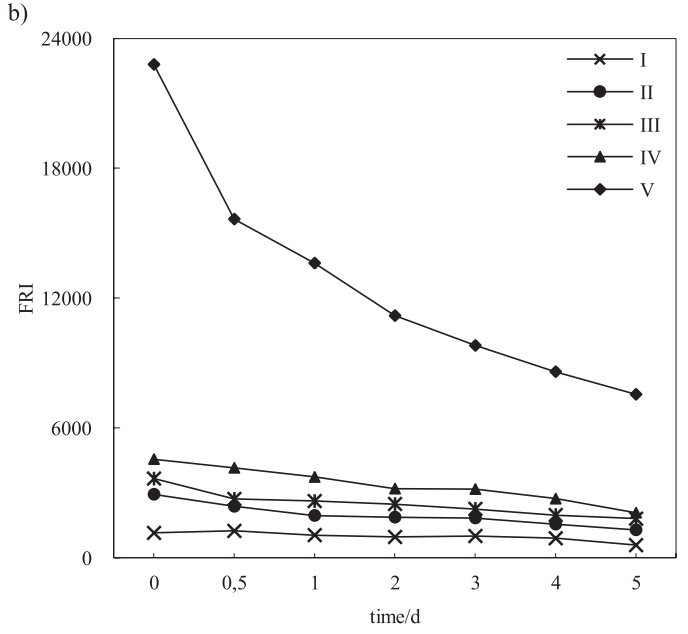

Fig. 7. Photodegradation characteristics of FRI in alpine soils.

of FDOM of them were different. Among them, the change of FDOM value of peat wetland soil in plateau was more complicated, maybe related to DOM source, optical characteristics and illumination.

\section{FRI of Soil DOM under Illumination}

Fluorescence regional integration(FRI) was used to process photodegradation data for subalpine forest and alpine peat wetland soil. Compared with the control group without light transmission. Both soil experimental groups showed good photodegradation characteristics, and five peaks of CDOM decreased with increase of irradiation time. As shown in Fig. 7, the peaks I, II and IV of alpine forest soil showed a certain rising tendency within 0.5 days, and the degradation rate of light irradiation DOM increased significantly after 0.5 days, while the peak III and V showed a significant decline along with the increase of light irradiation time. Except that the peak I of peat wetland soil showed a certain rising tendency within 0.5 days, and the degradation rate of light irradiation DOM increased significantly after 0.5 days, all the other peaks showed significant photodegradation characteristics during the experimental period. The DOM chemistry will change due to exposure to sunlight. Solar radiation generally reduces the ability of DOM to absorb ultraviolet light, converting large amounts of DOM to inorganic carbon [34], and alters the suitability of DOM as a microbial substrate. It can be roughly considered that the photodegradation experiment has improved the biodegradability of subalpine forest soil and alpine peat wetland soil, making two alpine soils more suitable as microbial matrixes. The photodegradation processes changes the properties of alpine soils, transforming the DOM of alpine soils into smaller molecules and making it easier for more fluxes to flow into the water body.

\section{D-COS Analysis of Soil FDOM under Illumination}

Two-dimensional correlation spectroscopy (2D-COS) was used to analyze the FDOM of forest soil and peat wetland soil in the eastern margin of QinghaiTibet Plateau. The external interference factors were light time. The synchronous, asynchronous and their characteristics of two different types of soil were shown in Fig. 8.

The synchrogram reflects the direction or degree of coordination of signal intensity change at two wave numbers [8]. There is an autocorrelation peak $(325 \mathrm{~nm})$ in the synchrogram of two kinds of soil, which indicates that the change degree of humic FDOM is the largest under the light interference. In addition, the position of the positive cross peak in the synchrogram of two kinds of soil in the eastern margin of Qinghai-Tibetan Plateau indicates that the fluorescence intensity of fulvic acid and UVA humic FDOM in the two kinds of soil is the largest under the light interference under the same conditions, there is the same change rule (i.e. photodegradation).

According to Noda rule, when the synchronous cross peak is positive, if the asynchronous cross peak is positive, then $\lambda 1$ changes before $\lambda 2$; if the asynchronous cross peak is negative, $\lambda 2$ changes faster than $\lambda 1$ [8]. There are three negative correlation peaks in the diagonals of FDOM, which are 335/300 nm, 400/335 nm and $500 / 335 \mathrm{~nm}$ respectively, while the spectral signals of FDOM are negative at $335 / 400 \mathrm{~nm}, 300 / 335 \mathrm{~nm}$, $300 / 400 \mathrm{~nm}$ and $335 / 500 \mathrm{~nm}$. Thus, the change order of FDOM in subalpine forest soil under light was: $300 \mathrm{~nm}>335 \mathrm{~nm}>400 \mathrm{~nm}>500 \mathrm{~nm}$. Similarly, the order of changes of soil FDOM in alpine peat wetland soil was: $500 \mathrm{~nm}>450 \mathrm{~nm}>335 \mathrm{~nm}>400 \mathrm{~nm}>270 \mathrm{~nm}$.

Based on 2D-COS analysis of forest soil and peat wetland soil in the eastern margin of Tibetan Plateau, it is found that there are different synchronous map and asynchronous map characteristics between the two kinds of soil. The results of synchronous map showed that FDOM in the two kinds of soil in the eastern margin of Qinghai-Tibet Plateau has degradation behavior under light. According to the asynchronous map, the degradation of tyrosine- and tryptophan- 

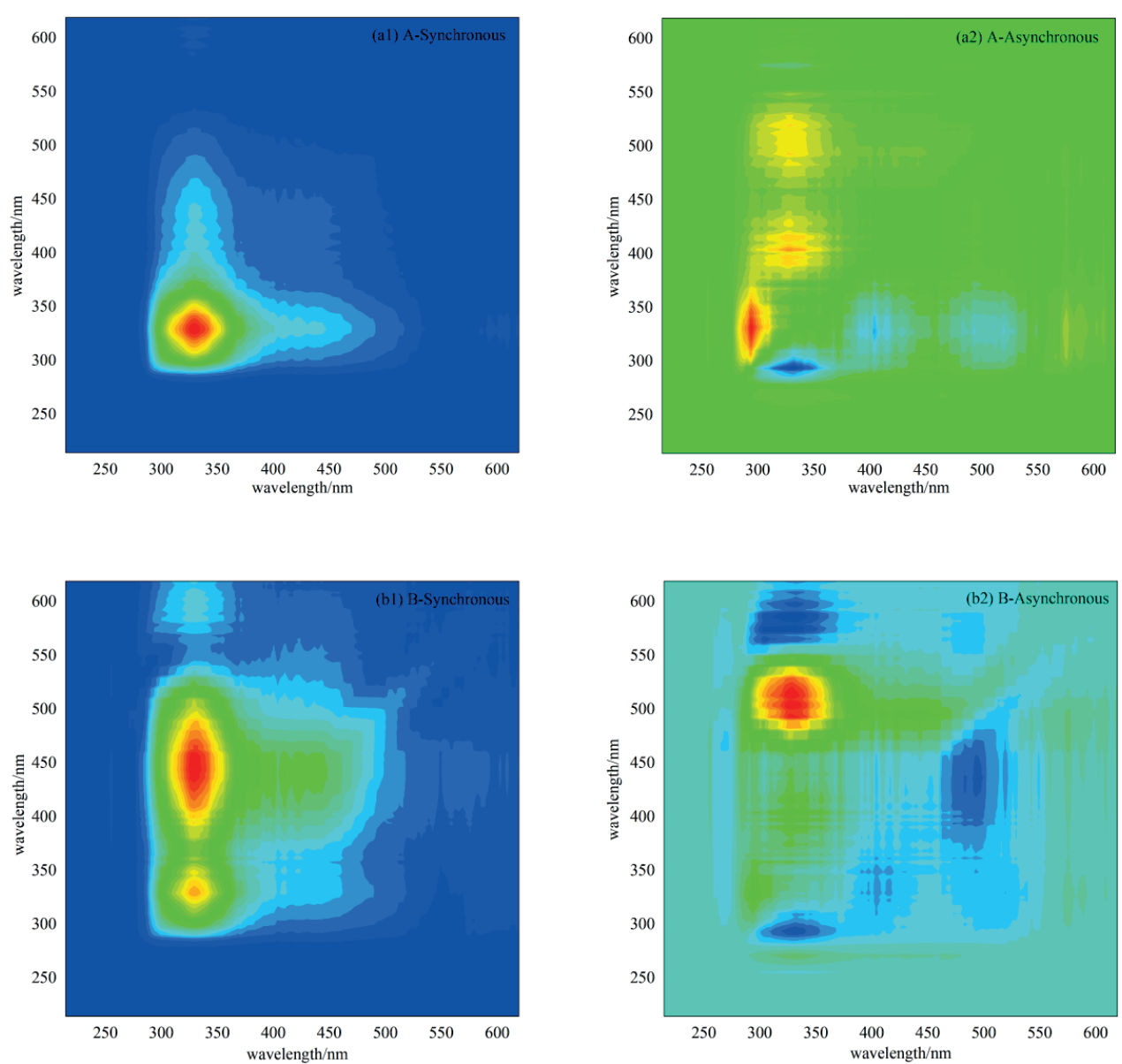

Fig. 8. Photodegradation characteristics of 2D-COS from FDOM in alpine soils. Note: Red represents a positive correlation and blue represents a negative correlation; higher color intensity indicates a stronger positive or negative correlation.

like FDOM in subalpine forest soil is prior to humuslike FDOM, while fulvic acid-like and humic acidlike FDOM showed higher susceptibility in alpine peat wetland soil.

\section{Conclusions}

In conclusion, DOM of the subalpine forest soil and alpine peat wetland soil in the eastern margin of Tibetan Plateau showed good photodegradation characteristics. The first-order decay constants and photodegradation rates of the alpine forest soil and peat soil were $0.0777 \mathrm{~d}^{-1}, 0.0907 \mathrm{~d}^{-1}$ and $42.06 \%, 45.47 \%$, respectively. In the process of illumination, the aromatic components $\left(\mathrm{SUVA}_{254}\right)$ and humification degree $\left(\mathrm{HIX}_{\mathrm{b}}\right)$ of CDOM in alpine soils decreased gradually with the increase of irradiation time. Additionally, the FDOM in alpine soils of the eastern margin of Tibetan Plateau showed four components (C1-C4), all components degraded in different degrees under light. According to the synchronous and asynchronous map, tyrosine- and tryptophan-like FDOM showed higher susceptibility in alpine forest soil, while fulvic acid-like and humic acid-like FDOM showed higher susceptibility in alpine peat wetland soil. As a whole, the photodegradation rate of DOM in alpine soil on the eastern margin of the Tibetan Plateau increased with the increase of light time, indicating that light may increase the instability of DOM in alpine soils.

\section{Acknowledgements}

This research was funded by the National Natural Science Foundation of China (No. 41271094).

\section{Conflict of Interest}

The authors declare no conflict of interest.

\section{References}

1. CHEN X., WANG J., CHEN J., ZHOU C., SUN G. Photodegradation of 2-(2-hydroxy-5-methylphenyl) benzotriazole (UV-P) in coastal seawaters: Important role of DOM. Journal of Environmental ences, 85, 129, 2019.

2. YANG L., ZHANG J., LIU K., YANG G. P. Spatiotemporal variability, size and photoreactivity of chromophoric 
dissolved organic matter in the Bohai Sea and the northern Yellow Sea. Journal of Marine Systems, 205, 19, 2020.

3. ISABEL R., EVA O.-R., OTILIA R., ELVIRA P.-V., RAFAEL M.-B., EMILIO O., C. Effect of Saharan dust inputs on bacterial activity and community composition inMediterranean lakes and reservoirs. Limnology and Oceanography, 54 (3), 869, 2009.

4. KIRCHMAN D. L., STEGMAN M. R., NIKRADIR M. P., COTTRELL M. T. Abundance, size, and activity of aerobic anoxygenic phototrophic bacteria in coastal waters of the West Antarctic Peninsula. Aquatic Microbial Ecology, 73 (1), 41, 2014.

5. BERG S.M., WHITING Q.T., HERRLI J.A., WINKELS R., WAMMER K.H., REMUCAL C.K. The Role of Dissolved Organic Matter Composition in Determining Photochemical Reactivity at the Molecular Level. Environmental Science \& Technology, 53 (20), 11725, 2019.

6. MOPPER K., KIEBER D.J., STUBBINS A. Marine Photochemistry of Organic Matter. In Biogeochemistry of Marine Dissolved Organic Matter, $2^{\text {nd }}$ ed.; DENNIS A. HAnsell, CRAIG A. CArlson, Eds., Publisher: Academic Press is an imprint of Elsevier, 389, 2015.

7. SUlZBERGER B., AUSTIN A.T., CORY R.M., ZEPP R.G., PAUL N.D. Solar UV radiation in a changing world: roles of cryosphere-land-water-atmosphere interfaces in global biogeochemical cycles. Photochemical \& Photobiological Sciences, 18 (3), 747, 2019.

8. NADO I., OZAKI Y. Two-dimensional correlation spectroscopy-applications in vibrational and optical spectroscopy. John Wiley \& Sons Ltd: The Atrium, Southern Gate, Chichester,West Sussex PO19 8SQ, England, 368, 2004 [In English].

9. PHONG D.D., HUR J. Non-catalytic and catalytic degradation of effluent dissolved organic matter under UVA-and UVC-irradiation tracked by advanced spectroscopic tools. Water Research, 105, 199, 2016.

10. HUR J., LEE B.-M. Characterization of copper binding properties of extracellular polymeric substances using a fluorescence quenching approach combining twodimensional correlation spectroscopy. Journal of Molecular Structure, 1069, 79, 2014.

11. ZHANG Y., WANG Y., ZHANG X., LI R. CHEN Y., MENG Q. Investigating the behavior of binding properties between dissolved organic matter (DOM) and $\mathrm{Pb}(\mathrm{II})$ during the soil sorption process using parallel factor analysis (PARAFAC) and two-dimensional correlation spectroscopy (2D-COS). Environmental Science and Pollution Research, 24 (32), 25156, 2017.

12. CHEN W., HABIBUL N., LIU X.Y., SHENG G.P., YU H.Q. FTIR and Synchronous Fluorescence Heterospectral Two-Dimensional Correlation Analyses on the Binding Characteristics of Copper onto Dissolved Organic Matter. Environmental Science \& Technology, 49 (4), 2052, 2015.

13. XU M., LIU W.J., BAI Y.G., TU Y. Biodegradation of dissolved organic matter in Lake Taihu during cyanobacterial blooms. China Environmental Science, 38 (9), 3494, 2018 [In Chinese].

14. JONES D., WILLETT V. Experimental evaluation of methods to quantify dissolved organic nitrogen (DON) and dissolved organic carbon (DOC) in soil. Soil Biology \& Biochemistry, 38, 991, 2006.

15. GABOR R.S., BURNS M.A., LEE R.H., ELG J.B., KEMPER C.J., BARNARD H.R., MCKNIGHT D.M. Influence of leaching solution and catchment location on the fluorescence of water-soluble organic matter. Environmental Science \& Technology, 49 (7), 4425, 2015.

16. XIE W., ZHANG S., RUAN L., YANG M., SHI W., ZHANG H., LI W. Evaluating soil dissolved organic matter extraction using three-dimensional excitationemission matrix fluorescence spectroscopy. Pedosphere, 27, 968, 2017.

17. LIU Y.-Y., QIN J.-H., LIU C., SUN H., TANG X.-Y., FAN S.-Y. Characteristics of Chromophoric Dissolved Organic Matter (CDOM) in Rivers of Western Sichuan Plateau Based on EEM-PARAFAC Analysis. Environmental Science, 39 (2), 720, 2018 [In Chinese].

18. JORG D., KLAUS K. Estimation of the hydrophobic fraction of dissolved organic matter in water samples using UV photometry. Water Research, 36 (20), 5037, 2002.

19. CHEN W., WESTERHOFF P., LEENHEER J. A., BOOKSH K. Fluorescence Excitation-Emission Matrix Regional Integration to Quantify Spectra for Dissolved Organic Matter. Environmental Science \& Technology, 37 (24), 5701, 2003.

20. ZHOU A., DU J., VARRONE C., WANG Y., WANG A., LIU W. VFAs bioproduction from waste activated sludge by coupling pretreatments with Agaricus bisporus substrates conditioning. Process Biochemistry, 4 (2), 283, 2014.

21. LIU S.Y., XU J., CHEN W.L., DAVID B. E., WU M., MA F. Impacts of potassium ferrate(VI) on the growth and organic matter accumulation, production, and structural changes in the cyanobacterium Microcystis aeruginosa. Environmental Science and Pollution Research, 24 (12), 11299, 2017.

22. FELLMAN J.B., HOOD E., D'AMORE D.V., EDWARDS R.T., WHITE D. Seasonal changes in the chemical quality and biodegradability of dissolved organic matter exported from soils to streams in coastal temperate rainforest watersheds. Biogeochemistry, 95 (2-3), 277, 2009.

23. ZHAO C., GAO S.J., ZHOU L., LI X., CHEN X., WANG C.C. Dissolved organic matter in urban forestland soil and its interactions with typical heavy metals: a case of Daxing District, Beijing. Environmental Science and Pollution Research, 26 (3), 2960, 2019.

24. LI S., CHEN Y.N., ZHANG J., SONG K., MU G., SUN C., JU H., JI M. The relationship of chromophoric dissolved organic matter parallel factor analysis fluorescence and polycyclic aromatic hydrocarbons in natural surface waters. Environmental Science \& Pollution Research, 25, $1428,2018$.

25. COBLE P.G. Characterization of marine and terrestrial DOM in seawater using excitation-emission matrix spectroscopy. Marine Chemistry, 51, 325, 1996.

26. LEE B.M., SEO Y.S., HUR J. Investigation of adsorptive fractionation of humic acid on graphene oxide using fluorescence EEM-PARAFAC. Water Research, 73, 242, 2015.

27. ZHOU Y., JEPPESEN E., ZHANG Y., SHI K., LIU X., ZHU G. Dissolved organic matter fluorescence at wavelength $275 / 342 \mathrm{~nm}$ as a key indicator for detection of point-source contamination in a large Chinese drinking water lake. Chemosphere, 144, 503, 2016.

28. LIU Y.Y., SUN H., LIU C., WANG X.Q. Characteristics of Chromophoric Dissolved Organic Matter (CDOM) in Natural Rivers of Western Sichuan Plateau. Environmental Science, 40 (12), 5318, 2019 [In Chinese].

29. HUGUET A., VACHER L., RELEXANS S., SAUBUSSE S., FROIDEFOND J.M., PARLANTI E. Properties of 
fluorescent dissolved organic matter in the Gironde Estuary. Organic Geochemistry, 40, 706, 2009.

30. OHNO T., FERNANDEZ I.J., HIRADATE S., SHERMAN

J.F. Effects of soil acidification and forest type on water soluble soil organic matter properties. Geoderma, 140 (12), 176, 2007.

31. FAN S.-Y., QIN J.-H., LIU Y.-Y., SUN H. Seasonal Variations of DOM Spectral Characteristics in the Surface Water of the Upstream Minjiang River. Environmental Science, 039 (010), 4530, 2018 [In Chinese].

32. LI Q., GUO X., CHEN L., LI Y., YUAN D., DAI B., WANG S. Investigating the spectral characteristic and humification degree of dissolved organic matter in saline- alkali soil using spectroscopic techniques. Frontiers of Earth Science, 11 (1), 76, 2017.

33. FICHOT C.G., BENNER R. The spectral slope coefficient of chromophoric dissolved organic matter (S275-295) as a tracer of terrigenous dissolved organic carbon in riverinfluenced ocean margins. Limnology and Oceanography, 57 (5), 1453, 2012.

34. GAO J., JIANG T., YAN J.L., WEI S. Q., WANG D.Y., LU S., LI L.L. Photobleaching of dissolved organic matter (DOM) from confluence of two rivers under natural solar radiation: a case study of Fujiang River-Jialingjiang River. Environmental Science, 35 (9), 3397,2014 [In Chinese]. 